\title{
The synthetic xylulose-1 phosphate pathway increases production of glycolic acid from xylose-rich sugar mixtures
}

Ceren Alkim ${ }^{1,2^{*}} \mathbb{0}$, Debora Trichez ${ }^{1,2}$, Yvan Cam ${ }^{1,2}$, Lucie Spina ${ }^{1,2}$, Jean Marie François ${ }^{1,2}$ and Thomas Walther ${ }^{1,2^{*}}$

\begin{abstract}
Background: Glycolic acid (GA) is a two-carbon hydroxyacid with applications in the cosmetic, textile, and medical industry. Microbial GA production from all sugars can be achieved by engineering the natural glyoxylate shunt. The synthetic (D)-xylulose-1 phosphate (X1P) pathway provides a complementary route to produce GA from (D)-xylose. The simultaneous operation of the X1P and glyoxylate pathways increases the theoretical GA yield from xylose by $20 \%$, which may strongly improve GA production from hemicellulosic hydrolysates.

Results: We herein describe the construction of an E. coli strain that produces GA via the glyoxylate pathway at a yield of $0.31,0.29$, and $0.37 \mathrm{~g} / \mathrm{g}$ from glucose, xylose, or a mixture of glucose and xylose (mass ratio: 33:66 \%), respectively. When the X1P pathway operates in addition to the glyoxylate pathway, the GA yields on the three substrates are, respectively, $0.39,0.43$, and $0.47 \mathrm{~g} / \mathrm{g}$. Upon constitutive expression of the sugar permease GalP, the GA yield of the strain which simultaneously operates the glyoxylate and X1P pathways further increases to $0.63 \mathrm{~g} / \mathrm{g}$ when growing on the glucose/xylose mixture. Under these conditions, the GA yield on the xylose fraction of the sugar mixture reaches $0.75 \mathrm{~g} / \mathrm{g}$, which is the highest yield reported to date.
\end{abstract}

Conclusions: These results demonstrate that the synthetic X1P pathway has a very strong potential to improve GA production from xylose-rich hemicellulosic hydrolysates.

Keywords: Escherichia coli, Glycolic acid, Synthetic pathway, Glucose, Xylose

\section{Background}

Glycolic acid (GA) is a two-carbon hydroxycarboxylic acid of considerable industrial interest. It is used as a tanning, peeling, and cleaning agent in the cosmetic and textile industry [1-3]. GA can be polymerized to produce biodegradable poly-glycolic acid (PGA) which is used as a packaging material for food and beverages [4]. Co-polymers of PGA and poly-lactic acid are used as absorbable suture and implant matrices [5, 6]. The market volume of GA continues to grow substantially and was reported to be 40 kilotons in 2014 [7].

At the industrial scale, GA is produced from fossil resources by treating formaldehyde with carbon monoxide

\footnotetext{
*Correspondence: alkim@insa-toulouse.fr; twalther@insa-toulouse.fr

1 LISBP, CNRS, INRA, INSA, Université de Toulouse, 135 Avenue de

Rangueil, 31077 Toulouse, France

Full list of author information is available at the end of the article
}

[8], or by treating chloroacetic acid with sodium hydroxide [2]. Growing concerns about the future availability of fossil resources and the environmental impact of their use $[9,10]$ have increased the interest in microbial production of GA. Until recently, sugar-based biosynthesis of GA was exclusively achieved by engineering the natural glyoxylate pathways in bacteria or yeast. GA production was accomplished by overexpressing isocitrate lyase and glyoxylate reductase enzymes, by deleting glyoxylate consuming reactions, and in some cases by attenuating isocitrate dehydrogenase activity ([11-15] and Table 1). The best results were obtained with an optimized Escherichia coli strain which produced $56 \mathrm{~g} / \mathrm{l} \mathrm{GA}$ at a yield of $0.52 \mathrm{~g} / \mathrm{g}$ in a fed-batch reactor using glucose as the carbon source ([11], Table 1).

Glycolic acid production through the glyoxylate pathway inevitably requires the decarboxylation of pyruvate 
Table 1 Production of glycolic acid (GA) by different engineered microorganisms

\begin{tabular}{|c|c|c|c|c|c|}
\hline Microorganism & Strain characteristics & Experimental conditions & Final GA conc. [g/L] & GA yield $[g / g]$ & References \\
\hline \multirow[t]{2}{*}{ Escherichia coli } & $\begin{array}{l}\text { Engineered glyoxylate shunt } \\
\text { Reduced expression of icd by weak promoter } \\
\text { Deletion of aceB, gcl, glcDEFGB, aldA, iclR, } \\
\text { edd-eda, poxB, ackA+pta, IdhA, mgs } A \text {, arc } A \\
\text { Overexpression of } g h r A \text { and aceA }\end{array}$ & $\begin{array}{l}\text { Shake flask } \\
\text { Mineral medium }+10 \mathrm{~g} / \mathrm{l} \\
\text { glucose }\end{array}$ & 5.14 & 0.52 & {$[12]$} \\
\hline & $\begin{array}{l}\text { Engineered glyoxylate shunt } \\
\text { Reduced expression of icd by weak promoter } \\
\text { Deletion of ace } B, g c l, g / c D E F G B, a l d A, i c l R, \\
\text { edd-eda, poxB, ackA+pta, arc } A \\
\text { Overexpression of } g h r A \text { and ace } A\end{array}$ & $\begin{array}{l}\text { Fed-batch fermentation } \\
\text { Mineral medium + glucose }\end{array}$ & 52.2 & 0.38 & \\
\hline $\begin{array}{l}\text { Kluyveromyces } \\
\text { lactis }\end{array}$ & $\begin{array}{l}\text { Engineered glyoxylate shunt } \\
\text { Deletion of MLS1, IDP2 } \\
\text { Overexpression of GLYR1 }\end{array}$ & $\begin{array}{l}\text { Fed batch fermentation } \\
\text { Mineral medium with xylose } \\
\text { and ethanol at mass ratio of } \\
1: 35\end{array}$ & 15 & $\mathrm{nr}$ & [13] \\
\hline $\begin{array}{l}\text { Corynebacterium } \\
\text { glutamicum }\end{array}$ & $\begin{array}{l}\text { Engineered glyoxylate shunt } \\
\text { Reduced expression of icd } \\
\text { Deletion of aceB } \\
\text { Overexpression of ghrA }\end{array}$ & $\begin{array}{l}\text { Shake flask } \\
\text { CGXII minimal medium (10.8 g/l } \\
\text { glucose + } 10.6 \mathrm{~g} / \text { l acetate })\end{array}$ & 5.30 & 0.18 & {$[15]$} \\
\hline E. coli & $\begin{array}{l}\text { Synthetic (D)-xylulose-1P pathway } \\
\text { Expression of } k h k C \text {, aldoB, ald } A \\
\text { Deletion of } x y|B, g| c D\end{array}$ & $\begin{array}{l}\text { Shake flask } \\
\text { Mineral medium + } 10 \mathrm{~g} / \mathrm{l} \\
\text { xylose }\end{array}$ & 4.30 & 0.46 & [16] \\
\hline \multirow[t]{3}{*}{ E. coli } & \multirow{3}{*}{$\begin{array}{l}\text { Engineered glyoxylate shunt } \\
\text { Deletion of aceB, glcB } \\
\text { Overexpression of ghrA, aceA, acek } \\
\text { Evolved strain }\end{array}$} & $\begin{array}{l}\text { Shake flask } \\
\text { Mineral medium }+8 \mathrm{~g} / \mathrm{l} \\
\text { glucose }\end{array}$ & 2.66 & 0.33 & [11] \\
\hline & & $\begin{array}{l}\text { Batch bioreactor } \\
\text { Mineral medium }+19 \mathrm{~g} / \mathrm{l} \\
\text { glucose }\end{array}$ & 8.96 & 0.48 & \\
\hline & & $\begin{array}{l}\text { Fed batch bioreactor } \\
\text { Mineral medium + glucose }\end{array}$ & 56.44 & 0.52 & \\
\hline \multirow[t]{3}{*}{ E. coli } & \multirow[t]{2}{*}{$\begin{array}{l}\text { Synthetic xylulose epimerase pathway } \\
\text { Expression of } P c-d t e, \text { fucK, fucA, aldA } \\
\text { Deletion of } g / c D, x y / B\end{array}$} & $\begin{array}{l}\text { Test tube } \\
\text { Mineral medium }+10 \mathrm{~g} / \mathrm{l} \\
\text { xylose }\end{array}$ & 3.43 & 0.46 & [14] \\
\hline & & $\begin{array}{l}\text { Batch bioreactor } \\
\text { Mineral medium }+>100 \mathrm{~g} / \mathrm{l} \\
\quad \text { xylose }\end{array}$ & 44.00 & 0.44 & \\
\hline & $\begin{array}{l}\text { Synthetic xylulose epimerase } \\
\text { pathway+engineered glyoxylate shunt } \\
\text { Expression of } P c-d t e, \text { fucK, fucA, aldA } \\
\text { Deletion of glcD, xylB, aceB, glcB, gcl } \\
\text { Overexpression of ghrA, aceA and acek }\end{array}$ & $\begin{array}{l}\text { Batch bioreactor } \\
\text { Mineral medium }+65 \mathrm{~g} / \mathrm{l} \\
\text { xylose }\end{array}$ & 40.00 & 0.63 & \\
\hline \multirow[t]{3}{*}{ E. coli } & Engineered glyoxylate shunt & $\begin{array}{l}\text { Shake flask } \\
\text { Mineral medium + } 10 \mathrm{~g} / \mathrm{l} \\
\text { glucose }(2 \mathrm{~g} / \mathrm{l} \text { tryptone, } 1 \mathrm{~g} / \mathrm{l} \\
\text { yeast extract) }\end{array}$ & 2.64 & 0.31 & This study \\
\hline & $\begin{array}{l}\text { Synthetic (D)-xylulose-1P pathway + engi- } \\
\text { neered glyoxylate shunt } \\
\text { Expression of } k h k C \text {, aldoB, aldA } \\
\text { Deletion of aceB, gcl, glcDEFGB, iclR, edd-eda, } \\
\text { arcA, icd, xylB } \\
\text { Overexpression of ghrA and aceA }\end{array}$ & $\begin{array}{l}\text { Shake flask } \\
\text { Mineral medium + } 10 \mathrm{~g} / \mathrm{l} \\
\quad \text { xylose }(2 \mathrm{~g} / \mathrm{l} \text { tryptone, } 1 \mathrm{~g} / \mathrm{l} \\
\text { yeast extract) }\end{array}$ & 2.24 & 0.43 & \\
\hline & $\begin{array}{l}\text { Synthetic (D)-xylulose-1P pathway + engi- } \\
\text { neered glyoxylate shunt } \\
\text { Expression of } k h k C \text {, aldoB, aldA } \\
\text { Deletion of aceB, gll, glcDEFGB, iclR, edd-eda, } \\
\text { arcA, icd, xylB } \\
\text { Overexpression of ghrA and aceA } \\
\text { galPexpressed from constitutive promoter } \\
\text { proD }\end{array}$ & $\begin{array}{l}\text { Shake flask } \\
\text { Mineral medium }+2,5 \mathrm{~g} / \mathrm{l} \\
\text { glucose and } 5 \mathrm{~g} / \mathrm{l} \text { xylose }(2 \mathrm{~g} / \mathrm{l} \\
\text { tryptone, } 1 \mathrm{~g} / \mathrm{l} \text { yeast extract })\end{array}$ & 3.73 & $0.63(0.75)^{*}$ & \\
\hline
\end{tabular}

* Estimated yield on the xylose fraction of the sugar mixture 
to provide the Krebs cycle substrate acetyl-CoA. Thus, the maximum yields for the glyoxylate pathway-dependent biosynthesis of GA from glucose or xylose are limited to $2 \mathrm{~mol} / \mathrm{mol}(0.84 \mathrm{~g} / \mathrm{g})$ and $1.66 \mathrm{~mol} / \mathrm{mol}(0.84 \mathrm{~g} / \mathrm{g})$, respectively. Recently, two synthetic pathways have been proposed that provide an improved stoichiometry for the synthesis of GA from (D)-xylose thereby increasing the maximum GA yield to $2 \mathrm{~mol} / \mathrm{mol}(1 \mathrm{~g} / \mathrm{g})$. Both pathways employ a carbon-conserving asymmetric aldolase cleavage of a $\mathrm{C} 5$ sugar that produces the $\mathrm{C} 2$ compound glycolaldehyde which is a direct precursor of GA, and the C3 compound DHAP $[14,16]$. Our group has developed the reaction sequence that employs xylulose-1 kinase, xylulose-1-phosphate (X1P) aldolase, and glycolaldehyde dehydrogenase activities [16]. These activities were provided by expressing the genes encoding human ketohexokinase $\mathrm{C}(k h k C)$, aldolase $\mathrm{B}($ aldo $B)$, and endogenous aldehyde dehydrogenase (ald $A$ ), respectively. We have termed this reaction sequence (D)-xylulose-1-phosphate pathway, and demonstrated the production of GA from pure xylose at a yield of $0.46 \mathrm{~g} / \mathrm{g}$ corresponding to $94 \%$ of the maximum yield of this pathway ([16], Table 1). Pereira and colleagues (2016) used a (D)-xylulose epimerase to transform (D)-xylulose into (D)-ribulose which was further converted to glycolaldehyde and DHAP by the consecutive action of (D)-ribulose- 1 kinase and (D)-ribulose-1 aldolase. They demonstrated GA production from pure (D)-xylose during simultaneous operation of the glyoxylate and xylulose epimerase pathways, and achieved a GA yield of $0.63 \mathrm{~g} / \mathrm{g}$ ([14], Table 1).

However, the utilization of pure xylose is an unrealistic scenario for the industrial production of GA. Although (D)-xylose can account for up to $80 \%$ of the sugar fraction of hemicellulosic hydrolysates, the glucose content in these feedstocks is still substantial and reaches up to $35 \%$ depending on raw material and hydrolyzation method [17]. Therefore, we investigated the potential of the synthetic X1P pathway to increase GA production on a synthetic sugar mixture that contained xylose and glucose at a ratio of 66 and $33 \%$ which we considered representative for a large panel of hemicellulosic hydrolysates. We engineered an E. coli strain to facilitate GA production through the glyoxylate pathway alone or in combination with the X1P pathway (Fig. 1). When GA was exclusively synthesized via the glyoxylate shunt, the strain produced GA at a yield of $0.37 \mathrm{~g} / \mathrm{g}$ from the sugar mixture. Upon the additional operation of the X1P pathway, the GA yield increased to $0.47 \mathrm{~g} / \mathrm{g}$, and reached $0.63 \mathrm{~g} / \mathrm{g}$ when the broad-range sugar permease GalP was additionally overexpressed from a constitutive promoter. Under these conditions, the GA yield on the xylose fraction of the sugar mixture reached $0.75 \mathrm{~g} / \mathrm{g}$, which corresponds to $75 \%$ of the theoretical maximum yield.

\section{Methods}

\section{Strains and plasmid construction}

Escherichia coli K-12 MG1655 (ATCC 47076) was used as the parental strain for all strain constructions in this study. The constructed strains are listed in Table 2. Gene deletions were introduced either by homologous recombination using the $\lambda$ Red recombinase system [18], in the case of $g l c D E F G B$, edd-eda, and $i c l R$, or by the phage transduction method [19], in the case of $a c e B, g c l, \operatorname{arcA}$, $i c d$ and $x y l B$. Gene deletion cassettes were amplified from pKD3 or pKD4 plasmids (Table 3) that have a chloramphenicol or a kanamycin resistance marker, respectively, using primers with $50 \mathrm{bp}$ homologies to the target locus. The deletion cassettes were purified using a PCR purification kit (Thermo Scientific) and transformed into the target strains using a standard protocol [20]. Cell lysates for phage transductions were prepared from single-gene deletion mutants of the Keio strain collection [21].

Expression of galP was rendered constitutive by replacing the natural chromosomal 5'-UTR of galP by the synthetic constitutive promoter proD [22]. The proD sequence was synthesized by Eurofins ${ }^{\mathrm{TM}}$. The kanamycine resistance cassette of the pKD4 plasmid and the synthetic promoter were individually amplified by Phusion polymerase (Biolabs) and fused by overlap extension PCR adding $50 \mathrm{bp}$ flanking sequences that were homologous to the target locus. The resulting DNA fragment was used to replace the natural galP promoter by homologous recombination [18].

Plasmid constructions: ace A and $g h r A$ genes were PCR amplified from Escherichia coli K-12 MG1655 genomic DNA using Phusion polymerase (Biolabs) with primers listed in Table 4. The DNA fragments were purified using a PCR purification kit (Thermo Scientific). The medium-copy pACT3 plasmid [23] was linearized with BamHI and HindIII (BioLabs), and the DNA fragments and the linearized vector were recombined using the In-Fusion ${ }^{\circledR}$ HD Cloning Kit (Clontech). The resulting plasmid was named pGS. The construction of plasmid pXIP, which expresses the genes encoding for aldehyde dehydrogenase from E. coli, and human ketohexokinase $\mathrm{C}$ and aldolase $\mathrm{B}$, respectively, was described previously [16]. The plasmids were transformed into different host strains alone or in combination. Strains and primers used in these studies are listed in Tables 2 and 3, respectively.

\section{Media and cultivation conditions}

Luria-Bertani (LB) medium [24] was used for preparations of precultures and genetic manipulations. Growth and production cultures were carried out in M9 minimal medium which contained (D)-glucose, (D)-xylose or 
Table 2 Escherichia coli strains used in this study

\begin{tabular}{|c|c|c|}
\hline Strain name & Genotype & Reference \\
\hline MG1655 & $F^{-} \lambda$-ilvG-rfb-50 rph-1 & ATCC 47076 \\
\hline NEB5-a & 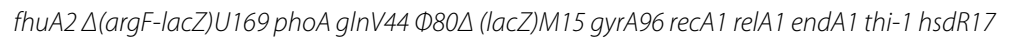 & NEB \\
\hline JW3536-2 & 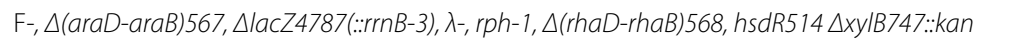 & {$[21]$} \\
\hline JW3974-1 & 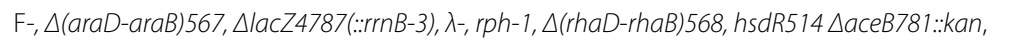 & [21] \\
\hline JW0495-1 & 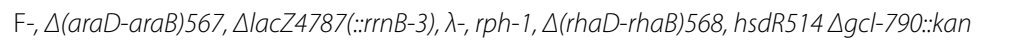 & [21] \\
\hline JW4364-1 & 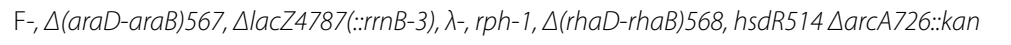 & [21] \\
\hline JW1122-2 & F-, $\Delta(\operatorname{araD}-a r a B) 567, \Delta l a c Z 4787(: . r r n B-3), \lambda-, r p h-1, \Delta(r h a D-r h a B) 568$, hsdR514 $\Delta i c d-724: . k a n$ & {$[21]$} \\
\hline Pen804 & $\triangle a c e B \triangle g l c D E F G B \triangle g c l \Delta e d d-e d a$ & This study \\
\hline Pen807 & Pen804 containing pGS & This study \\
\hline Pen847 & Pen804 $\triangle i c I R:: F R T$ pGS & This study \\
\hline Pen851 & Pen847 $\triangle \operatorname{arcA.:FRT~pGS~}$ & This study \\
\hline Pen1046 & Pen851 $\triangle i c d:: F R T$ & This study \\
\hline Pen1042 & Pen 1046 containing pGS & This study \\
\hline Pen1043 & Pen 1046 containing pX1P & This study \\
\hline Pen1044 & Pen 1042 containing pX1P & This study \\
\hline Pen1099 & Pen1046 galPproD containing pGS and pX1P & This study \\
\hline Pen1100 & Pen 1046 containing pACT3-empty & This study \\
\hline Pen880 & $\triangle a c e B \triangle g l c D E F G B \triangle g c l \Delta e d d$-eda $\triangle i c|R \triangle \operatorname{arc} A \Delta i c d \triangle x y| B$ & This study \\
\hline Pen1048 & Pen880 containing pX1P & This study \\
\hline Pen905 & Pen 1048 containing pGS & This study \\
\hline Pen979 & Pen880 galPproD containing pGS and pX1P & This study \\
\hline
\end{tabular}

Table 3 Plasmids used in this study

\begin{tabular}{|c|c|c|}
\hline Name & Relevant characteristics & Reference \\
\hline pCP20 & ori pSC101, Amp ${ }^{R}$, plasmid expressing Flp recombinase to remove Kan cassette & [42] \\
\hline pKD46 & ori oriR101 w/repA101ts, $\mathrm{Amp}^{\mathrm{R}}$, plasmid expressing $\lambda$ Red recombinase genes & {$[18]$} \\
\hline pKD3 & ori $\mathrm{R} 6 \mathrm{~K} \gamma, \mathrm{Cm}^{\mathrm{R}}$, source for cat cassette & {$[18]$} \\
\hline pKD4 & ori R6 Ky, Kan ${ }^{R}$, source for kan cassette & {$[18]$} \\
\hline pACT3 & orip15A, $\mathrm{Cm}^{\mathrm{R}}$ & {$[23]$} \\
\hline pEXT20 & ori colE1, Amp ${ }^{\mathrm{R}}$ & {$[23]$} \\
\hline pGS & pACT3 derivative carrying ghrA and aceA genes from E. coli & This study \\
\hline $\mathrm{pX} 1 \mathrm{P}$ & pEXT20 derivative carrying human genes $k h k-c$ and codon optimized aldo $B$, and aldA from E. coli & [16] \\
\hline
\end{tabular}

a mixture of (D)-glucose/(D)-xylose. Carbon source concentrations of M9 minimal medium are indicated in the text. M9 minimal medium contained $18 \mathrm{~g} / \mathrm{l} \mathrm{Na} \mathrm{HPO}_{4}$. $12 \mathrm{H}_{2} \mathrm{O}, 3 \mathrm{~g} / \mathrm{KH}_{2} \mathrm{PO}_{4}, 0.5 \mathrm{~g} / \mathrm{l} \mathrm{NaCl}, 2 \mathrm{~g} / 1 \mathrm{NH}_{4} \mathrm{Cl}, 0.5 \mathrm{~g} / \mathrm{l}$ $\mathrm{MgSO}_{4} \cdot 7 \mathrm{H}_{2} \mathrm{O}, 0.015 \mathrm{~g} / 1 \mathrm{CaCl}_{2} \cdot 2 \mathrm{H}_{2} \mathrm{O}, 0.010 \mathrm{~g} / \mathrm{FeCl}_{3}$, $0.006 \mathrm{~g} / \mathrm{l}$ Thiamine $\mathrm{HCl}, 0.4 \mathrm{mg} / \mathrm{l} \mathrm{NaEDTA} \cdot 2 \mathrm{H}_{2} \mathrm{O}$, $1.8 \mathrm{mg} / \mathrm{LCoCl}_{2} \cdot 6 \mathrm{H}_{2} \mathrm{O}, 1.8 \mathrm{mg} / \mathrm{l} \mathrm{ZnCl}_{2} \mathrm{SO}_{4} \cdot 7 \mathrm{H}_{2} \mathrm{O}$, $0.4 \mathrm{mg} / \mathrm{L} \mathrm{Na}_{2} \mathrm{MoO}_{4} \cdot 2 \mathrm{H}_{2} \mathrm{O}, 0.1 \mathrm{mg} / \mathrm{L} \mathrm{H}_{3} \mathrm{BO}_{3}, 1.2 \mathrm{mg} / \mathrm{L}$ $\mathrm{MnSO}_{4} \cdot \mathrm{H}_{2} \mathrm{O}, 1.2 \mathrm{mg} / \mathrm{L} \mathrm{CuCl} \cdot 2 \mathrm{H}_{2} \mathrm{O}$. The medium was buffered at pH 7 by addition of $20 \mathrm{~g} / \mathrm{l}$ MOPS (3-(N-morpholino) propanesulfonic acid) and sterilized by filtration (Merck Millipore ExpressPlus). 0.2 \% 'w/v' tryptone and $0.1 \%$ 'w/v' yeast extract were added to the M9 minimal medium from $5 \times$ sterile stock solutions to grow strains with an icd deletion. When required, ampicillin, kanamycin and chloramphenicol were added to the media at a concentration of 100,50 , and $25 \mu \mathrm{g} / \mathrm{mL}$, respectively. All chemicals were purchased from Sigma-Aldrich.

Pre-cultures were grown overnight at $200 \mathrm{rpm}$ shaking speed in $50 \mathrm{~mL}$ test tubes (BD Falcon) with $10 \mathrm{~mL}$ of M9 minimal medium supplemented with the carbon sources used in the production cultures. For inoculation of the cultures into $250 \mathrm{~mL}$ baffled shake flask, precultures were harvested by centrifugation for $5 \mathrm{~min}(4000 \times g$, Allegra 21-R, Beckman-Coulter) and washed once with sterile distilled water. Cells were inoculated at $\mathrm{OD}_{600} \sim 0.1$ 
Table 4 Primers used in this study

\begin{tabular}{|c|c|}
\hline Primer & Sequence $5^{\prime} \rightarrow 3^{\prime}$ \\
\hline \multicolumn{2}{|c|}{ Gene deletions by homologous recombination } \\
\hline glcDEFGB_fw & $\begin{array}{l}\text { GCGTCTTGATGGCGCTTTACCCGATGTCGACCGCACATCGGTACTGATGGCACTGCGTGAGCATGTCCCT } \\
\text { GGACTTGAGATCGTGTAGGCTGGAGCTGCTTC }\end{array}$ \\
\hline glcDEFGB_rev & $\begin{array}{l}\text { CGCGTAAACGCCAGGCGTGTAATAACGGTTCGGTATAGCCGTTTGGCTGTTTCACGCCGAGGAAGATTA } \\
\text { AATCGCTGGCCATATGAATATCCTCCTTAG }\end{array}$ \\
\hline edd eda_fw & $\begin{array}{l}\text { CGCGCGAGACTCGCTCTGCTTATCTCGCCCGGATAGAACAAGCGAAAACTTCGACCGTTCATC } \\
\text { GTTCGCAGTTGGCATGCGGGTGTAGGCTGGAGCTGCTTC }\end{array}$ \\
\hline edd eda_rev & $\begin{array}{l}\text { GCTTAGCGCCTTCTACAGCTTCACGCGCCAGCTTAGTAATGCGGTCGTAATCGCCCGCTTCCAGCGCATCTG } \\
\text { CCGGAACCCATATGAATATCCTCCTTAG }\end{array}$ \\
\hline iclR_fw & $\begin{array}{l}\text { CGCACCCATTCCCGCGAAACGCGGCAGAAAACCCGCCGTTGCCACCGCACCAGCGACTGGACAGGTTC } \\
\text { AGTCTTTAACGCGTGTAGGCTGGAGCTGCTTCG }\end{array}$ \\
\hline iclR_rev & $\begin{array}{l}\text { GCGCATTCCACCGTACGCCAGCGTCACTTCCTTCGCCGCTTTAATCACCATCGCGCCAAACTCGGTCAC } \\
\text { GCGGTCATCGGCATATGAATATCCTCCTTAG }\end{array}$ \\
\hline \multicolumn{2}{|c|}{ Construction of synthetic galP promoter } \\
\hline galP-KAN-fw & CCGCCCGCA CAATAACATCATTCTTCCTG ATCACGTTTCACCGCAGATTAGTGTAGGCTGGAGCTGCTTC \\
\hline galP-KAN-rev & GATAGGGACGACGTGGTGTTAGCTGTGCATATGAATATCCTCCTTAG \\
\hline galP-prom-fw & CACAGCTAACACCACGTCGT \\
\hline galP-prom-rev & $\begin{array}{l}\text { ACGTCATTGCCTTGTTTGACCGCCCCTGTTTTTTAGCGTCAGGCATATAATACCTCCTAAAGTTAAACAAAATT } \\
\text { ATTTGTAG }\end{array}$ \\
\hline Prom_galPproD_veri_fw & GCTGGCCTTTTTCTTTTGGATAG \\
\hline Prom_galPproD_veri_rev & ACCGATATCCAGGCCAAAGAG \\
\hline \multicolumn{2}{|c|}{ Verification Primers for gene knockouts } \\
\hline xylB_fw_2 & GTTATCGGTAGCGATACCGGGCATTTT \\
\hline xylB_rev_2 & GGATCCTGAATTATCCCCCACCCGGTCAGGCA \\
\hline aceB_verif_fw & CATGAATCCAACGCTGGATT \\
\hline aceB_verif_rev & CGAGGCTGTTGATGTAGCC \\
\hline fw gIDEF & TCCCGGACCTCGTGCACAGGTA \\
\hline glcB_verif_rev & CACACGCAGACGCAGAGTA \\
\hline gcl_verif_fw & TGTAGGTCTGAATTGCATAG \\
\hline gcl_verif_rev & CACGGGCATAACGAATCGCT \\
\hline eda_verif_rev & CCTTCCTCGGACTTCCGGTT \\
\hline eda_verif_rev & CCTTCCTCGGACTTCCGGTT \\
\hline iclR_verif2_fw & TTTCACCGCAAATACCGCCG \\
\hline iclR_verif2_rev & TGCAGCAATGTGTCGGCATAC \\
\hline arcA_verif_fw & CCTGAGGGAAAGTACCCACG \\
\hline arcA_verif_rev & GTTGTTGGGAACCAGTGTGC \\
\hline icd-verif-fw & CGACCTGCTGCATAAACACC \\
\hline icd-verif-rev & TGAACGCTAAGGTGATTGCA \\
\hline \multicolumn{2}{|l|}{ Cloning of ghrA and aceA } \\
\hline pACT ycdW-Fw & GAGCTCGGTACCCGGGGATCCAGGAGGCACACGATGGATATCATCTTTTATCACC \\
\hline Operon ycdW-Rev & TCATACGGTTCCTCCTTTAGTAGCCGCGTGCGCGGTCGACTT \\
\hline Operon aceA-Fw & GCACGCGGCTACTAAAGGAGGAACCGTATGAAAACCCGTACACAACAAATTG \\
\hline pACT aceA-Rev & CTCATCCGCCAAAACAGAAGCTTTTAGAACTGCGATTCTTCAGTGGA \\
\hline
\end{tabular}

Restriction sites are italicized and the start codons are shown in bold-italics

into $25 \mathrm{~mL}$ fresh M9 minimal medium containing an appropriate concentration of carbon source (see text) and cultivated in $250 \mathrm{~mL}$ baffled flask on a rotary shaker (Infors HT) running at $200 \mathrm{rpm}$. Growth was followed by measure of optical density at $600 \mathrm{~nm}\left(\mathrm{OD}_{600}\right)$ using a Biochrom Libra S11 spectrophotometer. Expression of the GA-producing pathways was induced by addition of isopropyl $\beta$-D-1-thiogalactopyranoside (IPTG) when the $\mathrm{OD}_{600}$ reached $\sim 0.8$. All cultivations were carried out at $30{ }^{\circ} \mathrm{C}$. 


\section{Analytical methods for extracellular metabolites quantifications}

Samples for metabolite quantification were regularly withdrawn from the cultures, centrifuged at 13,000 rpm for $5 \mathrm{~min}$ in a bench-top centrifuge (Eppendorf 5415D), filtered through a $0.2-\mu \mathrm{m}$ syringe filter, and stored at $-20{ }^{\circ} \mathrm{C}$ until further analysis. Quantification of sugars and organic acids was carried out by high performance liquid chromatography (HPLC) on an Ultimate 3000 system (Dionex, Sunnyvale, USA). The HPLC system was equipped with a cation-exchange column (Aminex HPX$87 \mathrm{H}-300 \times 7.8 \mathrm{~mm}, 9 \mu \mathrm{m}$, Biorad), an autosampler (WPS-3000RS, Dionex), a RI detector (RID 10A, Shimadzu), and an UV/VIS detector (SPD-20A, Shimadzu). The mobile phase was $1.25 \mathrm{mM} \mathrm{H}_{2} \mathrm{SO}_{4}$ at a flow rate of $0.5 \mathrm{~mL} / \mathrm{min}$. Column temperature was held at $35^{\circ} \mathrm{C}$.

\section{Results and discussion}

\section{Metabolic engineering for optimizing glycolic acid} production via the glyoxylate shunt

We first set out to engineer an E. coli strain for production of GA via the glyoxylate shunt by inactivating all annotated reactions that consume glyoxylic acid, i.e., malate synthase, encoded by $a c e B$ and $\operatorname{glcB}[25,26]$, glyoxylate carboligase, encoded by $g c l$ [27], and 2-oxo4-hydroxyglutarate aldolase, encoded by eda [28, 29]. Reoxidation of GA was prevented by deleting the glycolate oxidase-encoding glcDEFG operon [30]. Derepression of the glyoxylic acid-producing isocitrate lyase, AceA, was brought about by deletion of the transcriptional repressor, IclR [31, 32]. The strain which carried these deletions was transformed with plasmid pGS which expressed the isocitrate lyase and glyoxylate reductase encoding genes ace $A$ and $g h r A$, respectively [33, 34] (Fig. 1). The resulting strain Pen847 produced $0.69 \pm 0.23 \mathrm{~g} / \mathrm{l} \mathrm{GA}$ $(0.06 \mathrm{~g} / \mathrm{g}$ yield $)$ when cultivated on mineral medium supplemented with $10 \mathrm{~g} / \mathrm{l}$ glucose (Table 5 ). The additional deletion of the transcriptional repressor of Krebs cycle genes, ArcA [35] in strain Pen851 only slightly increased GA production to $0.80 \pm 0.15 \mathrm{~g} / \mathrm{l}(0.07 \mathrm{~g} / \mathrm{g}$ yield $)$. The isocitrate lyase from $E$. coli, AceA, has a low affinity for isocitrate $(\mathrm{Km}=0.89 \mathrm{mM})$ when compared to isocitrate dehydrogenase (Icd, $\mathrm{Km}=0.029 \mathrm{mM}$ ) [36]. Thus, it was possible that GA production was low because AceA was outcompeted by Icd. In agreement with this idea, the deletion of Icd in strain Pen1042 resulted in significant production of GA, which accumulated to $2.64 \pm 0.77 \mathrm{~g} / \mathrm{l}$ corresponding to a yield of $0.31 \mathrm{~g} / \mathrm{g}$ (Table 5). It is of note that the strains that carried the $\Delta i c d$ deletion were unable to grow on mineral medium. To restore their growth, the cultivation medium was supplemented with yeast extract and tryptone. However, no detectable quantities of GA were produced from these supplements when no additional sugar (glucose or xylose) was provided (not shown). Significant production of GA required the overexpression of GhrA and/or AceA from plasmid pGS, since strain Pen1100 which contained the empty pACT3 plasmid did not produce any GA but accumulated nearly $5 \mathrm{~g} / \mathrm{l}$ acetate (Table 5). These results are in qualitative agreement with the work of Dischert [12] and Deng [11] who reported that a strong decrease of Icd activity, brought about by decreasing the expression of icd or by overexpressing the Icd-inactivating protein kinase AceK, respectively, was required to achieve significant GA production.

\section{Co-function of glyoxylate and xylulose-1P pathways does not increase $G A$ production on pure $D$-xylose}

Since we wanted to quantify the increase of GA production from xylose that was due to the additional operation of the synthetic X1P pathway (see below), we first had to verify that expression of the enzymes that build up the X1P pathway have no unspecific side effects on GA production via the glyoxylate shunt. We therefore transformed plasmid $\mathrm{pX} 1 \mathrm{P}$, which carries the genes $k h k C$, aldoB, and ald $A$ genes that encode the X1P pathway enzymes, into the strains whose genotype was optimized for glyoxylate-dependent GA production and characterized them during growth on glucose. We found that the strains Pen1043 and Pen1048 which expressed pX1P alone produced no GA, thus confirming that pGS that bears GhrA and AceA genes was required for GA production through the glyoxylate shunt (Table 5). Strains Pen1044 and Pen905, which expressed both pGS and pX1P, produced GA at yields that were not statistically different from Pen1042 (Table 5). These results showed that the presence of the enzymes that build-up the X1P pathway does not significantly impact on GA production through the glyoxylate shunt. Thus, when studying GA production from xylose, which can be converted to GA through the glyoxylate and/or the X1P pathway, the observed differences could be clearly attributed to the function of the individual pathways, ruling out potential non-specific side effects of the X1P pathway enzymes.

After having demonstrated glyoxylate shunt-dependent GA production from glucose, we investigated GA production from xylose during simultaneous or individual function of the glyoxylate and X1P pathways. Strain Pen1042 assimilated xylose via the natural pentose phosphate pathway and produced GA through the glyoxylate shunt at a yield of $0.29 \mathrm{~g} / \mathrm{g}$ (Table 6). Absence of GA production in the isogenic strain Pen1100, which contained the empty pACT3 plasmid instead of pGS, confirmed that overexpression of GhrA and/or AceA was also required for GA production on xylose-containing medium. To enable xylose assimilation through the 
Table 5 Production of glycolic acid by different $E$. coli strains in medium containing glucose as carbon source

\begin{tabular}{|c|c|c|c|c|c|c|c|}
\hline \multirow[t]{2}{*}{ Strain name } & \multirow[t]{2}{*}{ Additional deletions } & \multirow[t]{2}{*}{ Plasmids $^{a}$} & \multirow{2}{*}{$\begin{array}{l}\text { Biomass } \\
\text { Yield [g/g] }\end{array}$} & \multicolumn{2}{|l|}{ Glycolic acid } & \multicolumn{2}{|l|}{ Acetate } \\
\hline & & & & Final conc. [g/l] & Yield [g/g] & Final conc. [g/l] & Yield $[\mathbf{g} / \mathbf{g}]$ \\
\hline Pen847 & & pGS & $0.30 \pm 0.03$ & $0.69 \pm 0.23$ & $0.06 \pm 0.01$ & $0.06 \pm 0.08$ & $0.01 \pm 0.01$ \\
\hline Pen851 & $\triangle \operatorname{arcA}$ & pGS & $0.30 \pm 0.01$ & $0.80 \pm 0.15$ & $0.07 \pm 0.00$ & $0.00 \pm 0.00$ & $0.00 \pm 0.00$ \\
\hline Pen 1042 & $\triangle \operatorname{arcA} \triangle i c d$ & $\mathrm{pGS}$ & $0.15 \pm 0.02$ & $2.64 \pm 0.77$ & $0.31 \pm 0.05$ & $0.93 \pm 0.58$ & $0.12 \pm 0.08$ \\
\hline Pen1100 & $\triangle \operatorname{arc} A \triangle i c d$ & pACT3 & $0.08 \pm 0.00$ & $0.00 \pm 0.00$ & $0.00 \pm 0.00$ & $4.80 \pm 0.04$ & $0.55 \pm 0.00$ \\
\hline Pen1043 & $\triangle \operatorname{arc} A \triangle i c d$ & $\mathrm{pX} 1 \mathrm{P}$ & $0.12 \pm 0.03$ & $0.00 \pm 0.00$ & $0.00 \pm 0.00$ & $3.11 \pm 0.96$ & $0.47 \pm 0.05$ \\
\hline Pen1044 & $\triangle \operatorname{arcA} \triangle i c d$ & $\mathrm{pGS}+\mathrm{pX} 1 \mathrm{P}$ & $0.17 \pm 0.03$ & $3.02 \pm 0.27$ & $0.37 \pm 0.03$ & $0.22 \pm 0.19$ & $0.03 \pm 0.02$ \\
\hline Pen 1048 & $\triangle \operatorname{arc} A \triangle i c d \triangle x y \mid B$ & $\mathrm{pX} 1 \mathrm{P}$ & $0.09 \pm 0.01$ & $0.00 \pm 0.00$ & $0.00 \pm 0.00$ & $4.44 \pm 0.13$ & $0.61 \pm 0.01$ \\
\hline Pen905 & $\triangle \operatorname{arc} A \triangle i c d \triangle x y \mid B$ & $\mathrm{pGS}+\mathrm{pX} 1 \mathrm{P}$ & $0.16 \pm 0.03$ & $2.96 \pm 0.25$ & $0.39 \pm 0.05$ & $0.00 \pm 0.00$ & $0.00 \pm 0.00$ \\
\hline
\end{tabular}

All strains carried the deletions $\triangle a c e B \triangle g l c D E F G B \triangle g c l \Delta e d d$-eda $\triangle i c l R$. Additional deletions are indicated in the table. Initial glucose concentration was $10 \mathrm{~g} / \mathrm{l}$. The mineral medium was supplemented with $2 \mathrm{~g} / \mathrm{l}$ tryptone and $1 \mathrm{~g} / \mathrm{l}$ yeast extract

a pGS expresses glyoxylate reductase and isocitrate lyase, encoded by ghrA and aceA. pX1P carries (D)-xylulose-1 kinase, (D)-xylulose-1 aldolase and glycolaldehyde dehydrogenase, encoded by $k h k C$, aldo $B$ and aldA, respectively. PACT3 is the empty plasmid. Results are presented as mean \pm STDV calculated from at least two replicate experiments

synthetic X1P pathway, the xylulose-5 kinase encoding gene $x y l B$ was additionally deleted in the host strain which carried the engineered glyoxylate shunt. To restore growth on xylose, this strain was transformed with plasmid pX1P, and the resulting strain Pen 1048 produced GA with a yield of $0.45 \mathrm{~g} / \mathrm{g}$, which corresponds to $89 \%$ of the maximum yield $(0.5 \mathrm{~g} / \mathrm{g})$ of the synthetic pathway. The GA yield of Pen 1048 was $55 \%$ higher than for Pen1042, indicating that GA production by the X1P pathway was more efficient than by the glyoxylate shunt. Contrary to our expectation, the simultaneous operation of the glyoxylate and X1P pathways in strain Pen905 did not result in a further increase of the GA yield which only reached $0.43 \mathrm{~g} / \mathrm{g}$ (Table 6). The reason for the failure to increase GA production by the co-function of both pathways during growth on pure xylose is not entirely clear. We speculate that the metabolic burden due to the propagation of two plasmids and the severely reduced Krebs cycle function due to the deletion of $i c d$ were responsible for the very strong growth retardation of this strain (not shown) which ultimately impaired efficient GA production under these conditions.

\section{Simultaneous function of the glyoxylate and (D)-xylulose-1P glycolic acid pathways strongly increases product yield during co-assimilation of glucose and xylose}

The development of the synthetic X1P pathway and its simultaneous operation with the engineered glyoxylate shunt was meant to increase GA production from xylose-rich second generation feedstocks. Hemicellulosic hydrolysates typically contain $50-75 \%$ xylose and $15-40 \%$ glucose together with smaller amounts of other sugars $[17,37]$. In order to test whether GA production from these feedstocks could be increased by the simultaneous operation of the X1P and glyoxylate pathways, we chose to incubate our strains on a sugar mixture that contained $2.5 \mathrm{~g} / \mathrm{l}$ glucose and $5 \mathrm{~g} / \mathrm{l}$ xylose, which corresponds to a mass ratio (33\%/66 \%) that is representative for hemicellulosic hydrolysates. Strains Pen1042 and Pen1044, which produce GA exclusively through the glyoxylate shunt, exhibited very similar GA yields of 0.37 and $0.42 \mathrm{~g} / \mathrm{g}$, respectively, that were calculated based on the total amounts of consumed sugars (glucose + xylose, Table 7). Due to the sequential utilization of glucose and xylose by these strains (not shown), the GA yield on the corresponding sugar fractions could be calculated individually. Interestingly, the GA yield on the xylose fraction of the sugar mixture $(0.47 \mathrm{~g} / \mathrm{g})$ was significantly higher than when these strains were incubated on pure xylose $(0.29 \mathrm{~g} / \mathrm{g})$. The reason for this behavior is not entirely clear, but it appears likely that more xylose could be converted to GA due to the very residual growth during utilization of the xylose fraction of the sugar mixture (compare to Fig. 2).

Strain Pen905, which operates both the glyoxylate and the X1P pathway, produced GA with a yield of $0.47 \mathrm{~g} / \mathrm{g}$. Thus, the simultaneous operation of the X1P and glyoxylate pathways conferred a $\sim 27 \%$ increased GA yield when compared to the exclusive operation of the glyoxylate pathway. The GA yield on the xylose fraction was $0.6 \mathrm{~g} / \mathrm{g}$ (Table 7) which is significantly higher than the GA yield which was reached by this strain on pure xylose $(0.43 \mathrm{~g} / \mathrm{g}$, Table 6). The simplest way to explain this difference is that the GA-producing pathways could be appropriately expressed in the sugar mixture during the exponential growth phase on glucose, whereas GA production on pure xylose remained comparatively low because growth 
Table 6 Production of glycolic acid by different $E$. coli strains in medium containing xylose as carbon source

\begin{tabular}{|c|c|c|c|c|c|c|c|}
\hline \multirow[t]{2}{*}{ Strain name } & \multirow[t]{2}{*}{ Additional deletions } & \multirow[t]{2}{*}{ Plasmids $^{\mathrm{a}}$} & \multirow{2}{*}{$\begin{array}{l}\text { Biomass } \\
\text { Yield }[g / g]\end{array}$} & \multicolumn{2}{|l|}{ Glycolic acid } & \multicolumn{2}{|l|}{ Acetate } \\
\hline & & & & Final conc. [g/l] & Yield [g/g] & Final conc. [g/l] & Yield $[g / g]$ \\
\hline Pen1100 & & pACT3 & $0.10 \pm 0.00$ & $0.00 \pm 0.00$ & $0.00 \pm 0.00$ & $4.20 \pm 0.01$ & $0.57 \pm 0.00$ \\
\hline Pen1042 & & pGS & $0.16 \pm 0.01$ & $2.11 \pm 0.49$ & $0.29 \pm 0.05$ & $0.16 \pm 0.23$ & $0.02 \pm 0.03$ \\
\hline Pen1044 & & $\mathrm{pGS}+\mathrm{pX1P}$ & $0.13 \pm 0.03$ & $1.57 \pm 0.24$ & $0.24 \pm 0.02$ & $0.55 \pm 0.11$ & $0.08 \pm 0.02$ \\
\hline Pen1048 & $\Delta x y \mid B$ & $\mathrm{pX} 1 \mathrm{P}$ & $0.09 \pm 0.01$ & $2.70 \pm 0.16$ & $0.45 \pm 0.01$ & $1.97 \pm 0.31$ & $0.33 \pm 0.04$ \\
\hline Pen905 & $\Delta x y / B$ & $p G S+p X 1 P$ & $0.08 \pm 0.01$ & $2.24 \pm 0.46$ & $0.43 \pm 0.05$ & $1.34 \pm 0.01$ & $0.26 \pm 0.02$ \\
\hline
\end{tabular}

All strains carried the deletions $\triangle a c e B \triangle g l c D E F G B \triangle g c l \Delta e d d$-eda $\triangle i c l R \triangle \operatorname{arc} A \Delta i c d$. Additional deletions are indicated in the table. Initial xylose concentration was $10 \mathrm{~g} / \mathrm{l}$. The mineral medium was supplemented with $2 \mathrm{~g} / \mathrm{l}$ tryptone and $1 \mathrm{~g} / \mathrm{l}$ yeast extract

a pGS expresses glyoxylate reductase and isocitrate lyase, encoded by ghrA and aceA. pX1P carries (D)-xylulose-1 kinase, (D)-xylulose-1 aldolase and glycolaldehyde dehydrogenase, encoded by $k h k C$, aldo $B$ and ald $A$, respectively. pACT3 is the empty plasmid. Results are presented as mean \pm STDV calculated from at least two replicate experiments

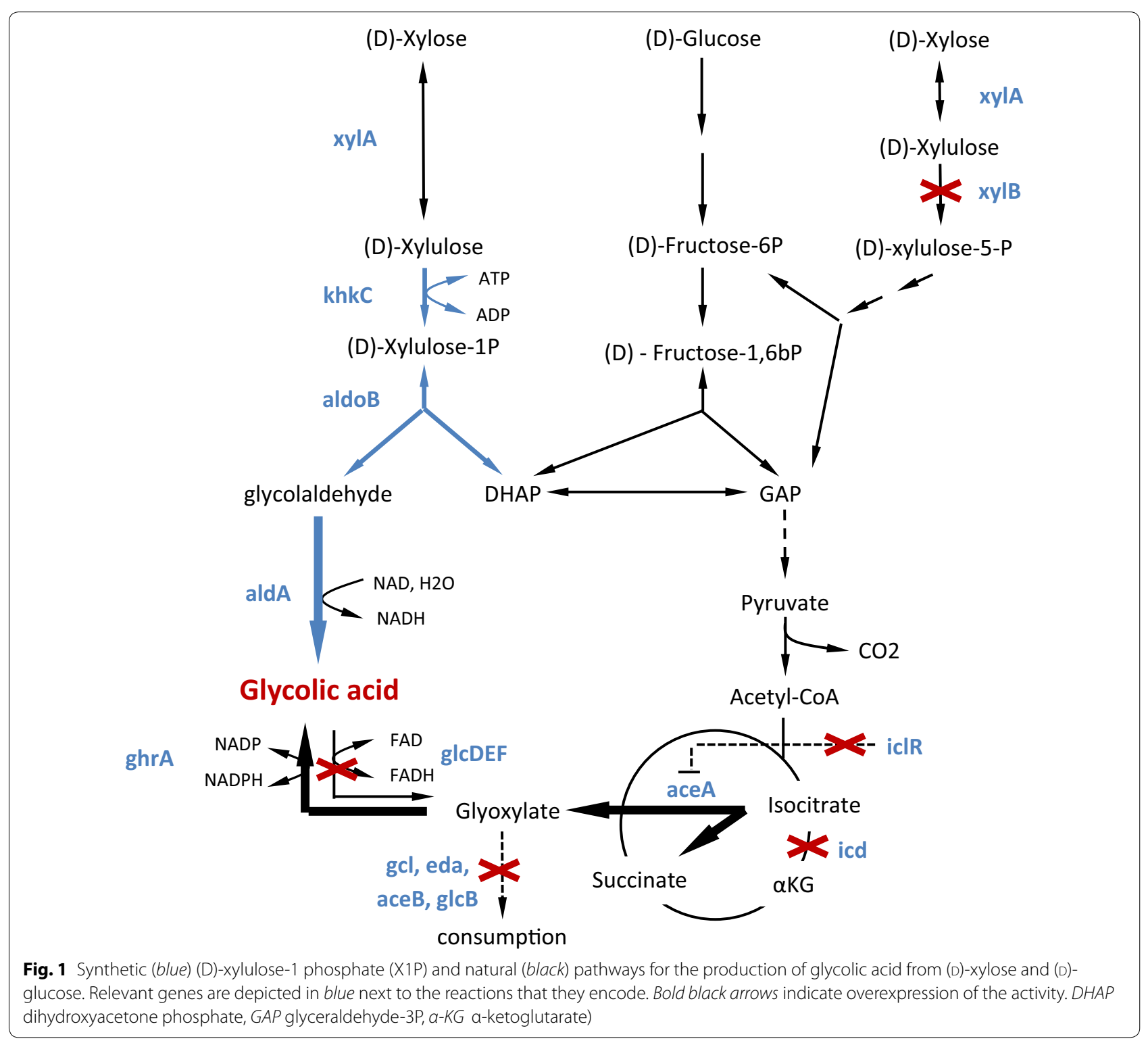


Table 7 Production of glycolic acid (GA) by different $E$. coli strains in medium containing glucose and xylose as carbon sources

\begin{tabular}{|c|c|c|c|c|c|c|c|}
\hline \multirow[t]{2}{*}{ Strain name } & \multirow[t]{2}{*}{ Additional modifications } & \multirow[t]{2}{*}{ Plasmids $^{\mathrm{a}}$} & \multirow{2}{*}{$\begin{array}{l}\text { Biomass } \\
\text { Yield } \\
{[\mathrm{g} / \mathrm{g}]}\end{array}$} & \multirow{2}{*}{$\begin{array}{l}\text { GA } \\
\text { Final conc. } \\
{[\mathrm{g} / \mathrm{l}]}\end{array}$} & \multicolumn{3}{|c|}{ GA yield on consumed sugarb } \\
\hline & & & & & $\begin{array}{l}G+X \\
{[g / g]}\end{array}$ & $\begin{array}{l}G \\
{[g / g]}\end{array}$ & $\begin{array}{l}X \\
{[g / g]}\end{array}$ \\
\hline Pen1042 & & $\mathrm{pGS}$ & $0.30 \pm 0.01$ & $1.58 \pm 0.11$ & $0.37 \pm 0.04$ & $0.30 \pm 0.05$ & $0.47 \pm 0.04$ \\
\hline Pen1044 & & $p G S+p X 1 P$ & $0.26 \pm 0.03$ & $2.41 \pm 0.64$ & $0.42 \pm 0.01$ & $0.36 \pm 0.09$ & $0.49 \pm 0.04$ \\
\hline Pen1099 & galpprod & $\mathrm{pGS}+\mathrm{pX} 1 \mathrm{P}$ & $0.24 \pm 0.00$ & $1.29 \pm 0.00$ & $0.33 \pm 0.00$ & $0.36 \pm 0.02$ & $0.35 \pm 0.02$ \\
\hline Pen905 & $\Delta x y / B$ & $\mathrm{pGS}+\mathrm{pX} 1 \mathrm{P}$ & $0.22 \pm 0.02$ & $1.98 \pm 0.68$ & $0.47 \pm 0.12$ & $0.37 \pm 0.12$ & $0.60 \pm 0.11$ \\
\hline Pen979 & $\Delta x y \mid B$ galPproD & $\mathrm{pGS}+\mathrm{pX} 1 \mathrm{P}$ & $0.23 \pm 0.02$ & $3.73 \pm 0.16$ & $0.63 \pm 0.04$ & $0.40 \pm 0.01$ & $0.75 \pm 0.05$ \\
\hline
\end{tabular}

All strains carried the deletions $\triangle a c e B \triangle g l c D E F G B \triangle g c l \Delta e d d$-eda $\triangle i c I R \triangle \operatorname{arc} A \Delta i c d$. Additional modifications are indicated in the table. Initial glucose and xylose concentrations were 2.5 and $5 \mathrm{~g} / \mathrm{l}$, respectively. The mineral medium was supplemented with $2 \mathrm{~g} / \mathrm{l}$ tryptone and $1 \mathrm{~g} / \mathrm{l}$ yeast extract

$G$ glucose, $X$ xylose, $G+X$ total sugar

a pGS expresses glyoxylate reductase and isocitrate lyase, encoded by ghrA and aceA. pX1P carries (D)-xylulose-1 kinase, (D)-xylulose- 1 aldolase and glycolaldehyde dehydrogenase, encoded by $k h k C$, aldo $B$ and ald $A$, respectively. pACT3 is the empty plasmid

b Results are presented as mean \pm STDV calculated from at least two replicate experiments
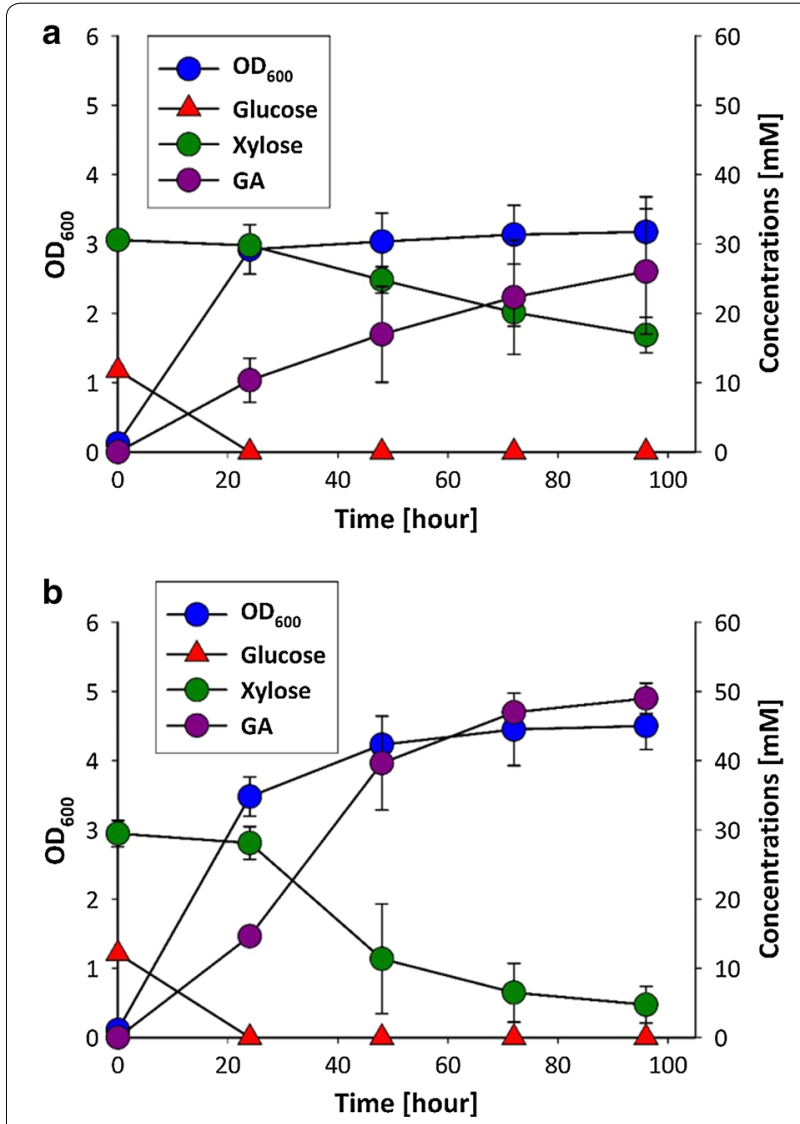

Fig. 2 Production of glycolic acid (GA) by optimized E. coli strains during growth on a synthetic mixture. a Strain Pen905 ( $\triangle a c e B$ $\triangle g / c D E F G B \triangle g c l \Delta e d d$-eda $\triangle i c I R \triangle a r c A \Delta i c d \triangle x y \mid B$ expressing $p G S$ and pX1P). b Strain Pen979 ( $\triangle a c e B \triangle g / C D E F G B \triangle g c l$ Ledd-eda $\triangle i c I R \triangle a r c A$ $\triangle i c d \triangle x y \mid B$ galPproD expressing $p G S$ and $P X 1 P)$. Initial glucose and xylose concentrations were 2.5 and $5 \mathrm{~g} / \mathrm{l}$, respectively. Cultivation was carried out in shake flasks at $30^{\circ} \mathrm{C}$ of the cells was extremely retarded resulting in incomplete expression of the GA pathways.

As shown in Fig. 2a, strain Pen905 first consumed all glucose in the medium before starting to utilize xylose. No growth was observed after glucose had been depleted and even after $100 \mathrm{~h}$ of cultivation the strain was only capable of consuming $\sim 50 \%$ of the xylose fraction. It was previously reported that stationary E. coli cells have a strongly decreased glucose uptake rate compared to exponentially growing cells $[38,39]$. Our results suggest that xylose uptake is also reduced in the absence of growth. In an attempt to facilitate co-assimilation of glucose and xylose and/or to increase the xylose uptake rate during stationary phase, we replaced the natural promoter of the broad-range sugar permease, GalP [40,41], by the strong constitutive promoter proD [22]. The resulting strain Pen979 continued to consume glucose and xylose sequentially, but exhibited strongly improved sugar uptake rates and consumed nearly all xylose during the monitored incubation period (Fig. 2b). As a consequence, the GA yield of strain Pen979 on total consumed sugar increased to $0.63 \mathrm{~g} / \mathrm{g}$, which corresponds to a gain of $\sim 70 \%$ compared to strain Pen1042 which operates the glyoxylate pathway alone. The GA yield on the xylose fraction reached $0.75 \mathrm{~g} / \mathrm{g}$ (Table 7). This value corresponds to $75 \%$ of the theoretical maximum GA yield which can be achieved during simultaneous operation of the glyoxylate and X1P pathways, and is the highest GA yield reported so far.

In contrast to the Pereira et al. [14], who reported a GA yield of $0.63 \mathrm{~g} / \mathrm{g}$ on pure xylose (Table 1 ), we chose to delete $i c d$ in our GA-producing strains, which resulted in the complete inactivation of the oxidative Krebs cycle branch thus increasing the carbon flux into the GA-producing glyoxylate 
shunt. This metabolic engineering strategy proved very effective for increasing the GA yield, but also imposed the need for supplementing the cultivation medium with an amino acid source (yeast extract and tryptone in the present study) to enable growth of our strains. It remains to be evaluated whether the need for amino acid supplements can be tolerated in an industrial process.

\section{Conclusions}

We have demonstrated that the simultaneous operation of the synthetic X1P and the engineered glyoxylate pathways greatly increases the GA yield on xylose-rich sugar mixtures. These results confirm the strong stoichiometric advantage that is provided by the synthetic X1P pathway during GA production from xylose containing feedstocks. However, further strain optimization is required to improve growth and fermentation characteristics of the production strains. It can be expected that genomic integration of the genes that are currently expressed from the pGS and pX1P plasmids will alleviate a significant metabolic burden, thus rendering growth of the cells more robust. In addition, our approach to enable GA production though the glyoxylate shunt by deleting icd strongly impaired growth of the cells. Thus, a more elaborate attenuation of Icd activity that maintains the ability of the cells to grow on mineral medium, e.g. by reducing its expression or by overexpressing aceK $[12,14]$, is clearly preferable when developing a strain for industrial applications. On the other hand, we reached a very high GA yield of $0.75 \mathrm{~g} / \mathrm{g}$ during the utilization of the xylose fraction of the sugar mixture. This shows that preventing growth during xylose utilization may be a promising approach to make full use of the stoichiometric advantage that is provided by the simultaneous operation of the glyoxylate and X1P pathways.

\section{Abbreviations \\ GA: glycolic acid; HPLC: high performance liquid chromatography; IPTG: isopropyl $\beta$-D-1-thiogalactopyranoside; $\mathrm{OD}_{600}$ : optical density at $600 \mathrm{~nm}$; PGA: poly-glycolic acid; pGS: plasmid which express the isocitrate lyase (aceA) and glyoxylate reductase ( $g h r A)$ encoding genes; pX1P: plasmid which express the ketohexokinase $C(k h k C)$, aldolase $B(a / d o B)$ and aldehyde dehydrogenase (aldA) encoding genes; RI: refractive index; UV/VIS: ultraviolet-visible; X1P: (D)-xylulose-1 phosphate.}

\section{Authors' contributions}

CA constructed mutant strains, performed shake-flask experiments, interpreted data and wrote the manuscript. DT carried out molecular genetic studies, constructed plasmids and interpreted the data. YC constructed mutant strains and participated shake-flask experiments. LS performed HPLC analyses and interpreted the data. TW conceived the project, oversaw the research, and wrote the manuscript. JMF oversaw the study and revised the manuscript. All authors read and approved the final manuscript.

\section{Author details}

1 LISBP, CNRS, INRA, INSA, Université de Toulouse, 135 Avenue de Rangueil, 31077 Toulouse, France. ${ }^{2}$ TWB, 3 rue Ariane, 31520 Ramonville-St. Agne, France.

\section{Acknowledgements}

The study was financed by the Toulouse White Biotechnology (TWB) consortium (Project: PENTOSYS). DT was supported by a post-doctoral grant (Science without borders program) provided by the CAPES foundation (Ministry of Education, Brazil). YC was supported by a post-doctoral grant provided by the Institut National de la Recherche Agronomique-Region Midi-Pyrénées (INRA, France). CA is supported by a post-doctoral grant from the Toulouse White Biotechnology Center

\section{Competing interests}

The authors declare that they have no competing interests.

\section{Funding}

The study was financed by the Toulouse White Biotechnology (TWB) consortium (Project: PENTOSYS). DT was supported by a post-doctoral grant (Science without borders program) provided by the CAPES foundation (Ministry of Education, Brazil). YC was supported by a post-doctoral grant provided by the Institut National de la Recherche Agronomique-Region Midi-Pyrénées (INRA, France).

Received: 25 May 2016 Accepted: 1 September 2016

Published online: 20 September 2016

\section{References}

1. Kataoka M, Sasaki M, Hidalgo AR, Nakano M, Shimizu S. Glycolic acid production using ethylene glycol-oxidizing microorganisms. Biosci Biotechnol Biochem. 2001. doi:10.1271/bbb.65.2265.

2. Miltenberger K. Hydroxycarboxylic acids aliphatic. Ullmanns Encycl Ind Chem. 2000. doi:10.1002/14356007.a13_507.

3. Rendon MI, Berson DS, Cohen JL, Roberts WE, Starker I, Wang B. Evidence and considerations in the application of chemical peels in skin disorders and aesthetic resurfacing. J. Clin. Aesthetic Dermatol. 2010;3:32-43.

4. Miller SA. Sustainable polymers: opportunities for the next decade. ACS Macro Lett. 2013;2:550-4.

5. Gilding DK, Reed AM. Biodegradable polymers for use in surgerypolyglycolic/poly(acetic acid) homo- and copolymers: 1. Polymer. 1979:20:1459-64

6. Langer R, Vacanti JP. Tissue engineering. 1993;920.

7. Sandström AG, Almqvist H, Portugal-Nunes D, Neves D, Lidén G, GorwaGrauslund MF. Saccharomyces cerevisiae: a potential host for carboxylic acid production from lignocellulosic feedstock? Appl Microbiol Biotechnol. 2014;98:7299-318.

8. John LD. Process for manufacture of glycolic acid. Google patents; 1939. https://www.google.com/patents/US2152852. Retrieved 21 March 2016.

9. Singh A, Nigam PS, Murphy JD. Renewable fuels from algae: an answer to debatable land based fuels. Bioresour Technol. 2011:102:10-6.

10. Zaldivar J, Nielsen J, Olsson L. Fuel ethanol production from lignocellulose: a challenge for metabolic engineering and process integration. Appl Microbiol Biotechnol. 2001;56:17-34.

11. Deng $Y$, Mao $Y$, Zhang X. Metabolic engineering of E. coli for efficient production of glycolic acid from glucose. Biochem Eng J. 2015;103:256-62.

12. Dischert W, Soucaille P. Method for producing high amount of glycolic acid by fermentation. Google patents. 2012. http://www.google.com/ patents/US20120315682. Retrieved 4 March 2016.

13. Koivistoinen OM, Kuivanen J, Barth D, Turkia H, Pitkänen J-P, Penttilä $M$, et al. Glycolic acid production in the engineered yeasts Saccharomyces cerevisiae and Kluyveromyces lactis. Microb Cell Factories. 2013;12:1-16.

14. Pereira B, Li Z-J, De Mey M, Lim CG, Zhang H, Hoeltgen C, et al. Efficient utilization of pentoses for bioproduction of the renewable two-carbon compounds ethylene glycol and glycolate. Metab Eng. 2016;34:80-7.

15. Zahoor A, Otten A, Wendisch VF. Metabolic engineering of Corynebacterium glutamicum for glycolate production. J Biotechnol. 2014;192:366-75.

16. Cam Y, Alkim C, Trichez D, Trebosc V, Vax A, Bartolo F, et al. Engineering of a synthetic metabolic pathway for the assimilation of (D)-xylose into value-added chemicals. ACS Synth Biol. 2015. doi:10.1021/ acssynbio.5b00103. 
17. Saha BC. Hemicellulose bioconversion. J Ind Microbiol Biotechnol. 2003;30:279-91.

18. Datsenko KA, Wanner BL. One-step inactivation of chromosomal genes in Escherichia coli K-12 using PCR products. Proc Natl Acad Sci USA. 2000;97:6640-5.

19. Malke H. Jeffrey H. Miller. A short course in bacterial genetics-a laboratory manual and handbook for Escherichia coli and related bacteria. Cold Spring Harbor 1992. Cold Spring Harbor Laboratory Press. ISBN: 0-87969349-5. J Basic Microbiol. 1993;33:278-278.

20. Chung CT, Niemela SL, Miller RH. One-step preparation of competent Escherichia coli: transformation and storage of bacterial cells in the same solution. Proc Natl Acad Sci USA. 1989;86:2172-5.

21. Baba T, Ara T, Hasegawa M, Takai Y, Okumura Y, Baba M, et al. Construction of Escherichia coli K-12 in-frame, single-gene knockout mutants: the Keio collection. Mol Syst Biol. 2006. doi:10.1038/msb4100050.

22. Davis JH, Rubin AJ, Sauer RT. Design, construction and characterization of a set of insulated bacterial promoters. Nucleic Acids Res. 2011:39:1131-41.

23. Dykxhoorn DM, Pierre R, Linn T. A set of compatible tac promoter expression vectors. Gene. 1996;177:133-6.

24. Bertani G. Studies on lysogenesis I: the mode of phage liberation by lysogenic Escherichia coli. J Bacteriol. 1951;62:293-300.

25. Molina I, Pellicer M-T, Badia J, Aguilar J, Baldoma L. Molecular characterization of Escherichia coli malate synthase g. Eur J Biochem. 1994;224:541-8.

26. Vanderwinkel $E$, de Vlieghere M. Physiologie et génétique de I'isocitritase et des malate synthases chez Escherichia coli. Eur J Biochem. 1968;5:81-90.

27. Krakow G, Barkulis SS, Hayashi JA. Glyoxylic acid carboligase: an enzyme present in glycolate-grown Escherichia coli. J Bacteriol. 1961;81:509-18.

28. Nishihara H, Dekker EE. Purification, substrate specificity and binding, $\beta$-decarboxylase activity, and other properties of Escherichia coli 2-keto4-hydroxyglutarate aldolase. J Biol Chem. 1972;247:5079-87.

29. Patil RV, Dekker EE. Cloning, nucleotide sequence, overexpression, and inactivation of the Escherichia coli 2-keto-4-hydroxyglutarate aldolase gene. J Bacteriol. 1992;174:102-7.

30. Pellicer MT, Badía J, Aguilar J, Baldomà L. glc locus of Escherichia coli: characterization of genes encoding the subunits of glycolate oxidase and the glc regulator protein. J Bacteriol. 1996;178:2051-9.
31. Cortay JC, Nègre D, Galinier A, Duclos B, Perrière G, Cozzone AJ. Regulation of the acetate operon in Escherichia coli: purification and functional characterization of the ICIR repressor. EMBO J. 1991;10:675-9.

32. Maloy SR, Nunn WD. Genetic regulation of the glyoxylate shunt in Escherichia coli K-12. J Bacteriol. 1982;149:173-80.

33. Matsuoka M, McFadden BA. Isolation, hyperexpression, and sequencing of the aceA gene encoding isocitrate lyase in Escherichia coli. J Bacteriol. 1988; 170:4528-36.

34. Nuñez MF, Pellicer MT, Badia J, Aguilar J, Baldoma L. Biochemical characterization of the 2-ketoacid reductases encoded by ycdW and yiaE genes in Escherichia coli. Biochem J. 2001;354:707-15.

35. Shalel LS, San KY, Bennett GN. Effect of oxygen on the Escherichia coli ArcA and FNR regulation systems and metabolic responses. Biotechnol Bioeng. 2005;89:556-64.

36. Ogawa T, Murakami K, Mori H, Ishii N, Tomita M, Yoshin M. Role of phosphoenolpyruvate in the NADP-isocitrate dehydrogenase and isocitrate lyase reaction in Escherichia coli. J Bacteriol. 2007;189:1176-8.

37. Walther T, Hensirisak P, Agblevor F. The influence of aeration and hemicellulosic sugars on xylitol production by Candida tropicalis. Bioresour Technol. 2001;76:213-20.

38. Doucette CD, Schwab DJ, Wingreen NS, Rabinowitz JD. a-ketoglutarate coordinates carbon and nitrogen utilization via enzyme I inhibition. Nat Chem Biol. 2011;7:894-901.

39. Chubukov V, Sauer U. Environmental dependence of stationary-phase metabolism in bacillus subtilis and Escherichia coli. Appl Environ Microbiol. 2014:80:2901-9.

40. Henderson PJ, Giddens RA, Jones-Mortimer MC. Transport of galactose, glucose and their molecular analogues by Escherichia coli K12. Biochem J. 1977;162:309-20.

41. Maiden MCJ, Davis EO, Baldwin SA, Moore DCM, Henderson PJF. Mammalian and bacterial sugar transport proteins are homologous. Nature. 1987;325:641-3.

42. Cherepanov PP, Wackernagel W. Gene disruption in Escherichia coli: TcR and KmR cassettes with the option of Flp-catalyzed excision of the antibiotic-resistance determinant. Gene. 1995;158:9-14.

\section{Submit your next manuscript to BioMed Central and we will help you at every step:}

- We accept pre-submission inquiries

- Our selector tool helps you to find the most relevant journal

- We provide round the clock customer support

- Convenient online submission

- Thorough peer review

- Inclusion in PubMed and all major indexing services

- Maximum visibility for your research

Submit your manuscript at www.biomedcentral.com/submit
() Biomed Central 